\title{
The pregnant woman with heart disease: management of pregnancy and delivery
}

\author{
P. G. Pieper
}

Published online: 9 November 2011

(C) The Author(s) 2011. This article is published with open access at Springerlink.com

\begin{abstract}
Women with heart disease are at risk of cardiac complications during pregnancy and delivery. Risk assessment should be performed in these women, and the management of pregnancy and delivery should be planned accordingly. Depending on the risk, women should be cared for in specialised centres, regional centres or a combination of both. Multidisciplinary teams must be involved in the care of these women. Adequate organisation of care and communication between the team members is important to prevent complications.
\end{abstract}

Keywords Pregnancy $\cdot$ Heart disease $\cdot$ Management . Delivery

\section{Introduction}

Adult women with heart disease frequently pursue pregnancy. Pregnancy induces haemodynamic changes, which include a $40 \%$ increase in plasma volume and cardiac output as well as a marked reduction in systemic vascular resistance. Additionally haemostatic changes lead to hypercoagulability. The physiological changes of pregnancy are often well tolerated by women with heart disease, but may also induce complications such as heart failure, arrhythmias and thromboembolic events [1-4]. The peripartum period constitutes an extra risk, since during and after delivery cardiac demand increases due to uterus contractions, anxiety, pushing, autotransfusion of the contracting uterus post-delivery, and blood loss. The risk of

P. G. Pieper $(\bowtie)$

Department of Cardiology, University Medical Centre Groningen, University of Groningen,

PO Box 30.001, 9700 RB Groningen, the Netherlands

e-mail: p.g.pieper@umcg.nl pregnancy should be assessed before and during pregnancy, and management of pregnancy and delivery must be planned accordingly [5, 6]. Adequate pregnancy management includes involvement of a multidisciplinary team that ensures appropriate and well-organised care during pregnancy and peripartum. In the first article of this series, a system for risk assessment was described [5]. This second article illustrates that untoward complications can arise unexpectedly even in women with heart disease who are at the favourable end of the risk spectrum and it describes the requirements for the management of pregnancy and delivery in order to prevent, recognise and treat complications and guide these women safely through this highly desired life event.

\section{Case description and comment}

A 28-year-old woman presented with a pregnancy wish. She had a history of subvalvular membranous aortic stenosis. At 7 and at 14 years of age surgical resection of the membrane was performed. As a young adult, she developed recurrent severe subvalvular stenosis which became symptomatic. When she was 21 years old, the membrane was radically resected through a Morrow procedure and the left ventricular (LV) outflow tract was widened with a Konno procedure. After this operation she was symptom-free and needed no medication. Her echocardiogram demonstrated septal akinesia with an LV diastolic diameter of $57 \mathrm{~mm}$ at the basal level but a normal midventricular diameter of $52 \mathrm{~mm}$. LV ejection fraction was $50 \%$. The aortic valve was abnormal with grade I regurgitation and valvular aortic stenosis with peak and mean gradients of 27 and $15 \mathrm{mmHg}$. It was concluded that she had a slightly elevated risk of heart failure and arrhythmias during pregnancy because of her mild aortic valve dysfunction and local wall motion abnormality of the LV. She was graded as pregnancy 
risk WHO class II [5-7] (low-moderate risk). She became pregnant in 2007 and was followed in the cardiac service at 20, 26 and 34 weeks. Her LV diameters and ejection fraction as well as the aortic stenosis and regurgitation were stable. She developed dyspnoea on exertion during the second trimester without signs of heart failure, which was attributed to the pregnancy in combination with moderate overweight. During the last weeks of pregnancy she started to gain weight, a total of $8 \mathrm{~kg}$ in 2 weeks time, and she felt more dyspnoeic. The patient, a medical doctor herself, suggested that she had fluid retention due to heart failure, but the junior gynaecologist assured her that this weight gain was normal and the cardiologist was not consulted. Delivery was induced at 39 weeks and a healthy daughter was delivered by secondary caesarean section. Two months after delivery she was admitted because of bradycardia due to 2 nd degree $\mathrm{AV}$ block and a DDDR pacemaker was inserted. Unfortunately, at the first echocardiogram after delivery her LV diameters were significantly larger than pre-pregnancy, 65 and $58 \mathrm{~mm}$ at basal and midventricular levels, respectively, with preserved ejection fraction of $50 \%$. She remained in NYHA class II post-pregnancy. It was considered that she may have had an unrecognised period of heart failure in the weeks before delivery which was a likely explanation for the LV dilatation. Alternatively, ventricular pacing may have caused the dilatation post-pregnancy.

It can be concluded that the care of this woman was suboptimal in the last weeks of her pregnancy. Her pregnancy risk was adequately assessed as low to moderate, therefore routine cardiac supervision was not planned after the 34th week. However, the cardiologist should have been consulted both when she complained of excessive weight gain and increasing dyspnoea and when the delivery started. We can only speculate if this would have made any difference in outcome. Nevertheless, if she had been diagnosed with heart failure, medication and/or early delivery might have prevented damage. In the CEMACH (Confidential Enquiry on Maternal Death) report [8], it appeared that substandard care was an important contributing factor to the death of many mothers. Substandard care included insufficient communication between team members and inappropriate delegation of tasks to junior doctors. Though outcome was more favourable than in the CEMACH report, these factors may have also played a role in our case. Adequate organisation of care with skilled multidisciplinary teams working according to standard operating procedures is important to prevent unnecessary complications.

\section{Management of pregnancy}

It is advisable that all women with cardiac disease have one consultation in a specialised centre for counselling, risk estimation and formulation of a management plan. This should preferably take place before pregnancy, or otherwise as early in pregnancy as possible. It should be decided where the woman will receive cardiology and obstetric care during pregnancy. Three levels of care can be distinguished. These levels of care are comparable with the care recommended in the ESC guidelines for the management of grown-up congenital heart disease and are modified for pregnant women with heart disease according to disease complexity and pregnancy risk [9]. Level 1 represents care for highly complex and high-risk (WHO class III or IV) lesions, for which exclusive care in a specialist unit is advisable, usually monthly or bimonthly. Level 2 represents care for moderately complex lesions and low to moderate risk of pregnancy (WHO II); these women can be managed in a shared care model by collaboration of a specialist and a regional cardiac and obstetric service and usually need cardiac follow-up once per trimester. Women with simple lesions and low pregnancy risk (WHO class I) are classified for level 3 care which means that they can be managed entirely in a regional hospital. For these women, cardiac follow-up can be limited to once or twice during the pregnancy. Examples are provided in Table 1.

When a woman uses medication, she needs to be advised about the continuation, cessation or change of her medication before she gets pregnant. ACE inhibitors, angiotensin II receptor blockers and statins are contraindicated throughout pregnancy and must be discontinued, preferably before pregnancy. Amiodarone should also be discontinued. Vitamin $\mathrm{K}$ antagonists should be avoided in the first trimester and be replaced by unfractionated heparin or low-molecular-weight heparin. However, in women with mechanical valves, continuation of vitamin $\mathrm{K}$ antagonists can be considered, especially when daily dose requirements are low, because of the higher risk of valve thrombosis with heparins. Most $\beta$-blockers can be continued if necessary, except atenolol. Also calcium antagonists appear to be well tolerated and can be used during pregnancy when necessary, though experience is limited $[6,10]$. In all women with a pregnancy wish or who are pregnant, thromboembolic risk should be assessed according to the schedules presented in the ESC guidelines for the management of cardiovascular diseases during pregnancy [6], and when applicable thromboprophylaxis and/or compression stockings can be implemented when pregnancy occurs.

During pregnancy, standard cardiac follow-up for most women will consist of clinical assessment and echocardiography. Additionally depending on the underlying lesion and on symptoms, 24-hour ECG monitoring can be performed. Exercise testing should preferably be performed pre-pregnancy to assist in risk estimation, but can be performed in asymptomatic pregnant women to a heart rate of $80 \%$ of the maximal predicted heart rate [6]. It is evident 
Table 1 Levels of care for pregnant women with heart disease

\begin{tabular}{|c|c|c|}
\hline Level 1 & Care in specialised centre & $\begin{array}{l}\text { Women with WHO risk class III or IV } \\
\text { Uncorrected cyanotic heart disease } \\
\text { Pulmonary hypertension/Eisenmenger syndrome } \\
\text { Dilatation of aorta } \\
\text { Severe mitral or aortic or pulmonary stenosis } \\
\text { Transposition of the great arteries } \\
\text { Fontan circulation } \\
\text { Ebstein's disease } \\
\text { Dilated or hypertrophic cardiomyopathy } \\
\text { Mechanical valve prosthesis } \\
\text { Other corrected congenital heart disease with significant residual abnormalities }\end{array}$ \\
\hline Level 2 & $\begin{array}{l}\text { Shared care, collaboration between } \\
\text { regional and specialised centre }\end{array}$ & $\begin{array}{l}\text { Women with WHO risk class } \mathrm{II}^{\mathrm{a}} \\
\text { Mild or moderate mitral or aortic stenosis } \\
\text { Moderate mitral or aortic regurgitation } \\
\text { Moderate pulmonary stenosis } \\
\text { Corrected coarctation of aorta } \\
\text { Corrected atrioventricular septal defect } \\
\text { Corrected tetralogy of Fallot }^{\mathrm{b}}\end{array}$ \\
\hline Level 3 & Care in regional centre & $\begin{array}{l}\text { Women with WHO class } \mathrm{I}^{\mathrm{a}} \\
\text { Small or repaired ventricular septal defect } \\
\text { Small or repaired atrial septal defect } \\
\text { Repaired ductus arteriosus } \\
\text { Mild pulmonary stenosis } \\
\text { Mild mitral or aortic regurgitation }\end{array}$ \\
\hline
\end{tabular}

${ }^{\mathrm{a}} \mathrm{WHO}$ risk class $=$ World Health Organisation risk class for pregnant women with cardiac disease [2-4]

${ }^{\mathrm{b}}$ If no significant residual abnormalities

that radiation must be avoided if possible, but for vital indications procedures involving radiation may be performed, if no other possibilities are available. Radiation exposure of the foetus is limited for most procedures and acute foetal risk does not usually exist. Few data are available to judge the safety of magnetic resonance imaging during pregnancy, but it is probably safe at least after the first trimester and provided gadolinium is avoided [11].

A multidisciplinary team should be involved in the management of the pregnancy. The core members of this team are the cardiologist and the gynaecologist, and when delivery approaches the anaesthetist and neonatologist. For some women a haematologist or a cardiac surgeon need to be involved. It should never be forgotten that the general practitioner is an important member of the team who should be well informed about the course of the pregnancy, since he may get involved at any stage of the pregnancy and especially in emergency situations occurring outside the hospital. A nurse practitioner can be a very useful member of the team and can serve as the coordinator. Adequate communication between team members is of paramount importance. The cardiologist should formulate the cardiac risks of the pregnancy and both cardiologist and gynaecol- ogist must readily inform all team members about the results of examinations and about complications that occur.

\section{Management of delivery}

At the end of the second trimester the multidisciplinary team should formulate a plan for the delivery. This plan should include:

- timing of delivery (spontaneous or induction)

- mode of delivery (vaginal delivery or caesarean section)

- whether or not rhythm observation or haemodynamic monitoring is necessary

- analgesia/anaesthesia

- advice about medication during delivery and lactation

- a plan for observation after delivery

Timing of delivery

Most women with heart disease can be allowed to go into spontaneous labour [6]. Sometimes it may be preferable to 
induce delivery at a previously scheduled time, for example in women with mechanical valves in order to be able to manage anticoagulation more appropriately. In some women early induced delivery may be preferred. This can be the case for instance in women with heart failure or with progressive aortic dilatation.

\section{Mode of delivery}

Several studies show that caesarean section is performed more often in women with heart disease than in a healthy population $[12,13]$. For most cardiac patients, however, vaginal delivery is preferred and caesarean section is reserved for obstetric indications, since caesarean section is associated with more blood loss and higher thromboembolic and infection risk. Examples of situations in which primary caesarean section should be considered are start of labour while on oral anticoagulants (because of risk of foetal intracranial bleeding), Marfan syndrome with diameter of the ascending aorta $>45 \mathrm{~mm}$, acute or chronic dissection, and acute heart failure [6]. When vaginal delivery is chosen, it should be decided whether the woman can be allowed to push or if an assisted vaginal delivery is preferable. The benefit of avoiding haemodynamic fluctuations resulting from pushing must be weighed against an increased risk of perineal trauma, haemorrhage and foetal head injury with forceps or vacuum delivery. For most women, pushing may be preferred above primary assisted delivery [14].

\section{Rhythm observation and haemodynamic monitoring}

Rhythm observation should be scheduled on an individual basis in women with previous severe arrhythmias. Intraarterial pressure recording may be useful in women with haemodynamic instability.

\section{Analgesia/anaesthesia}

Regional anaesthesia is often useful to reduce the cardiac stress of vaginal delivery and is necessary for caesarean delivery. Single-shot spinal anaesthesia can cause hypotension and should be avoided in cardiac patients with fixed cardiac output or with shunting. Epidural, combined epidural/spinal, and continuous spinal anaesthesia is safe for most cardiac patients. However, caution remains necessary to avoid excessive reduction in systemic vascular resistance $[6,14]$.

Advice concerning medication

Administration of oxytocin is useful to reduce haemorrhage. It should be given as a slow intravenous infusion and not as a rapid bolus to avoid hypotension. When anticoagulation is necessary, especially in women with mechanical valves, warfarin or low-molecular-weight heparin should be replaced by unfractionated heparin $36 \mathrm{~h}$ before induction of labour. Unfractionated heparin should be discontinued 4-6 h before delivery and restarted $4-6 \mathrm{~h}$ after delivery. When the mother is on chronic medication advice concerning lactation should be formulated according to the new guidelines [6].

\section{Observation after delivery}

After delivery, haemodynamic changes occur due to caval decompression and volume loading through autotransfusion of blood from the contracting uterus. Therefore, the risk of complications is increased. Discharge from hospital should routinely be delayed until at least $24-72 \mathrm{~h}$ after delivery, depending on underlying heart disease and risk estimation.

\section{Conclusion}

Women with heart disease need care from a multidisciplinary team to guide them safely through pregnancy. Careful management of pregnancy and delivery is required. Adequate organisation of care and communication between all professionals involved in the care of these women is of paramount importance to prevent complications. The new European Society of Cardiology guidelines on the management of cardiovascular diseases during pregnancy [6] provide the relevant medical information and recommendations to assist multidisciplinary teams in their task.

Open Access This article is distributed under the terms of the Creative Commons Attribution Noncommercial License which permits any noncommercial use, distribution, and reproduction in any medium, provided the original author(s) and source are credited.

\section{References}

1. Drenthen W, Boersma E, Balci A, On behalf of the ZAHARA investigators, et al. Predictors of pregnancy complications in women with congenital heart disease. Eur Heart J. 2010;31:2124-32.

2. Siu SC, Sermer M, Colman JM, et al. Prospective multicenter study of pregnancy outcomes in women with heart disease. Circulation. 2001;104(5):515-21.

3. Drenthen W, Pieper PG, Roos-Hesselink JW, et al. Outcome of pregnancy in women with congenital heart disease. A literature review. J Am Coll Card. 2007;49(24):2302-11.

4. Pieper PG, Balci A, van Dijk AP. Pregnancy in women with prosthetic heart valves. Neth Heart J. 2008;16:406-11.

5. Pieper PG. Pre-pregnancy risk assessment and counselling of the cardiac patient. Neth Heart J 2011; Sep 7 (Epub ahead of print) 
6. Regitz-Zagrosek V, Blomstrom Lundqvist C, Borghi C et al. ESC guidelines on the management of cardiovascular diseases during pregnancy of the European Society of Cardiology. Eur Heart J. 2011; Aug 26 (Epub ahead of print; doi:10.1093/eurheartj/ehr218)

7. Thorne S, McGregor A, Nelson-Piercy C. Risk of contraception and pregnancy in heart disease. Heart. 2006;92:1520-5.

8. CEMACH, London, 2007. Confidential enquiry into maternal and child health. Perinatal Mortality 2005: England, Wales and Northern Ireland.

9. Deanfield J, Thaulow E, Warnes C, et al. Management of grown up congenital heart disease. Eur Heart J. 2003;24:1035-84.

10. Newstead-Angel J, Gibson PS. Cardiac drug use in pregnancy: safety, effectiveness and obstetric implications. Expert Rev Cardiovasc Ther. 2009;7:1569-80.
11. De Wilde JP, Rivers AW, Price DL. A review of the current use of magnetic resonance imaging in pregnancy and safety implications for the fetus. Progr Biophys Mol Biol. 2005;87:33553.

12. Yap SC, Drenthen W, Pieper PG, et al. On behalf of the ZAHARA Investigators. Risk of complications during pregnancy in women with congenital aortic stenosis. Int J Cardiol. 2008;126:240-6.

13. Balci A, Drenthen W, Mulder BJ, et al. Pregnancy in women with corrected tetralogy of Fallot: occurrence and predictors of adverse events. Am Heart J. 2011;161:307-13.

14. Fernandes SM, Arendt KA, Landsberg MJ, et al. Pregnant women with cardiac disease: cardiac, anesthetic and obstetrical implications. Expert Rev Cardiovasc Ther. 2010;8:439-48. 